\title{
Percepções e crenças sobre fauna cinegética em uma região semiárida do Brasil
}

Este estudo investiga percepções e crenças relacionadas à fauna cinegética na comunidade Cruz, no município de Delmiro Gouveia, Estado de Alagoas. As informações foram obtidas por meio de entrevistas semiestruturadas e conversas informais realizadas com 17 moradores no período de maio a dezembro de 2016. Segundo a percepção dos entrevistados, as espécies cinegéticas mais abundantes são gambá ( $n=12)$, rolinha $(n=10)$ e mocó $(n=6)$. A respeito da fauna silvestre que se tem tornado rara na região, os entrevistados citaram tatu $(n=10)$, tamanduá $(n=4)$, seriema $(n=4)$ e porco-do-mato $(n=4)$. As representações da fauna cinegética na comunidade Cruz se caracterizam por mitos, crenças, saberes e tabus alimentares, que constituem práticas culturais e ecológicas relevantes, uma vez que as crenças associadas aos animais disciplinam a prática de caça e são importantes estratégias para uso sustentável dos recursos faunísticos.

Palavras-chave: Fauna cinegética; Conservação; Representação social.

\section{Perceptions and beliefs on game fauna in a semi-arid region of Brazil}

\begin{abstract}
This study investigates perceptions and beliefs related to the huntable fauna in the Cruz community, in the municipality of Delmiro Gouveia, State of Alagoas, Brazil. The information was obtained through semi-structured interviews and informal conversations with 17 residents from May to December 2016. According to the interviewees' perception, the most abundant hunting species are opossum ( $n=12)$, rolinha (a little pigeon) $(n=10)$ And mocó (a rodent, $n=6)$. Regarding the fauna that has become rare in the region, the interviewees cited armadillo $(n=10)$, anteater $(n=4)$, seriema (a bird with $70 \mathrm{~cm}$ height) $(n=4)$ and porcupine $(n=4)$. The representations of the game fauna in the Cruz community are characterized by myths, beliefs, knowledge and food taboos, which are relevant cultural and ecological practices, since the beliefs associated to the animals discipline the practice of hunting and are important strategies for the sustainable use of the fauna resources.

Keywords: Hunting fauna, Conservation, Social representation.
\end{abstract}

Topic: Fundamentos de Biodiversidade

Reviewed anonymously in the process of blind peer.
Received: 14/02/2017

Approved: 21/04/2017
Jaciara Raquel Barbosa de Lima

Universidade do Estado da Bahia, Brasil

http://lattes.cnpq.br/7011512117536969

raquelzinha.lima@hotmail.com

Carlos Alberto Batista dos Santos

Universidade do Estado da Bahia, Brasil

http://lattes.cnpq.br/0024544164324027

cacobatista@yahoo.com.br

Emmanuel Duarte Almada

Universidade do Estado de Minas Gerais, Brasil

http://lattes.cnpq.br/4322718529316744

andrade.emmanuel@gmail.com
Eraldo Medeiros Costa Neto

Universidade Estadual de Feira de Santana, Brasil

http://lattes.cnpq.br/2521953264550977

eraldont@hotmail.com
Referencing this:

LIMA, J. R. B.; SANTOS, C. A. B.; ALMADA, E. D.; COSTA NETO, E. M.. Percepções e crenças sobre fauna cinegética em uma região semiárida do Brasil. Revista Ibero-Americana de Ciências Ambientais, v.8, n.3, p.23-30, 2017. DOI: http://doi.org/10.6008/SPC21796858.2017 .003 .0003 


\section{INTRODUÇÃO}

A interação do homem com a fauna silvestre tem sido representada em toda a história da humanidade, sendo explorada em desenhos rupestres antes mesmo do desenvolvimento da agricultora (VERDADE, 2004). Para Alves et al. (2008), a conexão estabelecida entre os seres humanos e as demais espécies animais envolve relações extremamente importantes para as sociedades humanas, uma vez que estas mantêm interação de dependência ou codependência da fauna. Essa interdependência tem sido explicada pela hipótese da biofilia, a qual propõe que o ser humano teve $99 \%$ da história evolutiva associada a outros seres vivos, o que lhe permitiu desenvolver um sistema informacional acerca das espécies e do ambiente, traduzidos em saberes, crenças e práticas culturais relacionados com os animais de cada lugar (SANTOS-FITA et al., 2007).

Esse conhecimento é transmitido de geração a geração, especialmente por meio da tradição oral, revelada nas atividades produtivas e nas representações simbólicas do ambiente (DIEGUES, 1996). Não obstante, o conhecimento local pode também ser transmitido por meio da observação de atividades locais, da utilização de utensílios, adornos e vestimentas e de cultos (BAPTISTA, 2015).

O estudo das diferentes interpretações que o homem dá sobre os animais pode ser abordado segundo a teoria da representação social, definida como o senso comum que se tem sobre determinado tema, incluindo preconceitos, ideologias e características que especificam as atividades das pessoas (MOSCOVICl, 2005). As formas de representações dos animais nas coletividades podem influenciar o modo como os animais são explorados pelas diferentes culturas, já que o comportamento humano ante os animais é formado pelo conjunto de valores, conhecimentos e percepções, bem como pela natureza das relações que os seres humanos mantêm com esses organismos (DREWS, 1999).

Portanto, é preciso discutir a relevância das representações dentro da coletividade e como elas influenciam as decisões que os seres humanos tomam individualmente (REIGOTA, 2010), uma vez que é por meio da cultura que o homem em sociedade interage com o ambiente natural (LEFF, 2009), na qual a diversidade cultural não pode estar dissociada da diversidade biológica. Assim, este estudo objetivou investigar percepções e crenças relacionadas à fauna cinegética na comunidade Cruz, no município de Delmiro Gouveia/AL.

\section{METODOLOGIA}

A pesquisa foi desenvolvida no período de maio a dezembro de 2016. Os dados foram coletados por meio de aplicação de questionário semiestruturado, complementado por entrevistas livres e conversas informais (ALBUQUERQUE et al., 2008). As entrevistas foram aplicadas a 17 moradores que caçam ou já caçaram animais silvestres, abordando-se temas a respeito da percepção sobre a fauna cinegética e as alterações das populações da fauna ao longo do tempo, além de crenças, restrições e conhecimento dos caçadores. A escolha dos informantes foi realizada por meio da técnica denominada 'bola de neve' ou Snowball, proposta por Balley (1994). 
No início de cada entrevista foi explicado aos entrevistados os objetivos e natureza do trabalho a fim de obter a permissão deles para registro das informações, quando tomaram conhecimento do conteúdo do Termo de Consentimento Livre e Esclarecido (TCLE) e concordaram em participar da pesquisa. A identidade dos entrevistados foi mantida em sigilo, sendo identificados com a letra ' $M$ ', inicial de morador, seguida do número sequencial em que ocorreu a entrevista. O estudo foi realizado no povoado Cruz, localizado no município de Delmiro Gouveia/AL, conforme ilustrado na figura 1. Os resultados foram analisados qualitativamente segundo o modelo de união das diversas competências individuais (MARQUES, 1991), e os conhecimentos tradicionais foram comparados com aqueles correspondentes ou correlacionados na literatura científica, conforme utilizado por Marques (1995).

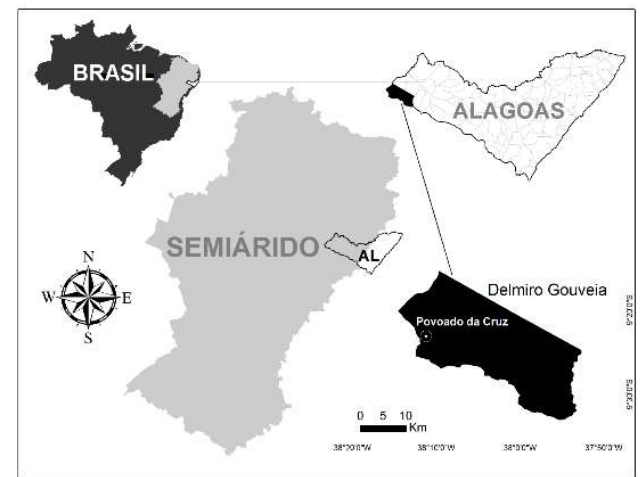

Figura 1: Localização do povoado Cruz, no município de Delmiro Gouveia/AL.

\section{RESULTADOS E DISCUSSÃO}

Segundo a percepção dos entrevistados, as espécies da fauna silvestre mais abundantes na comunidade Cruz são gambá $(n=12)$, rolinha $(n=10)$ e mocó $(n=6)$. Eles atribuem essa abundancia à capacidade reprodutiva desses animais, o que os torna alvos mais fácil para os caçadores. A respeito da fauna silvestre que se tem tornado rara na comunidade, os entrevistados citaram tatu $(n=10)$, tamanduá $(n=4)$, seriema $(n=4)$ e porco-do-mato $(n=4)$. Segundo um informante, esses animais eram encontrados facilmente ao redor das casas e nas roças, entretanto, em virtude do desmatamento e da caça, o número deles tem diminuído.

Com relação aos animais silvestres, os entrevistados reconhecem a importância e o papel para o equilíbrio do ecossistema, como pode ser observado no depoimento a seguir: "É um bem importante para a natureza" (M-1); "São importantes porque fazem parte da cadeia alimentar" (M-4); "O governo tem que tomar providência, estão se acabando de fome, um dia desse vi dois gambás novos desmaiando de fome" (M-10).

Como destacam Diegues et al. (2001), o conhecimento que as populações humanas detêm do ambiente é fruto da manipulação diária dos recursos naturais, em que as espécies são objeto de conhecimento, domesticação, uso e fonte de inspiração para mitos e rituais nas sociedades tradicionais. Assim, por meio da interação que o homem mantém com o meio ambiente, as populações tradicionais 
acumulam um vasto conhecimento sobre as espécies naturais, a exemplo dos caçadores que apresentam conhecimentos sobre habitat, hábitos, ecologia e características da fauna cinegética com a qual interagem.

Esse conhecimento, fruto da dependência que as populações têm com a natureza, muitas vezes complementam o conhecimento científico, podendo ser utilizado no planejamento de estratégias para conservação da fauna silvestre (POSEY, 1984).

A respeito da disponibilidade das espécies em função do tempo, os entrevistados relataram que a quantidade desses animais vem diminuindo, apontando a seca, o desmatamento e atividade extensiva de caça como elementos responsáveis pela redução da fauna local: "Diminuiu e muito, porque acabaram, desmatou a caatinga. Aí, é difícil eles ficar"; "Tem reduzido por causa da seca, falta comida pras caças"; "Por causa do desmatamento diminuiu muito" (M-1); "Acabou porque tem muita gente caçando" (M-7); "A caça tem acabado por causa do desmatamento e pela falta de alimentos pra caças" (M-14). Observa-se nessas afirmações que os caçadores reconhecem a caça como atividade impactante para a conservação da fauna silvestre.

Para os entrevistados, a caça é uma atividade que requer experiência, como pode ser observado no relato a seguir: "Para ser um bom caçador tem que ter muita experiência, conhecer a lua, o lugar, os rastros dos animais, saber qual animal é só pelo rastro" (M-8). "Choveu, sai o sol, é bom tempo de caçar teiú, eles sai pra procurar comida" (M-5). "O teiú é bom no inverno, quando chove e no outro dia sai um solzinho é o melhor" (M-7). "O horário bom depende do animal: peba é das 18 às 21, já o tamanduá é depois das 23 horas" (M-10). "Durante a noite, depende do animal” (M-1). "Melhor horário pra caçar é meia-noite" (M-3). "Melhor tempo de caça é no verão, porque quando chove os animais não desce a serra pra comer" (M-17). "Verão, porque agora no inverno os animais estão de filhotes" (M-2). "Tem dia que não é bom para caçar, na sexta-feira mesmo não é" (M4).

Nesses depoimentos, pode-se observar que os caçadores detêm conhecimento sobre as características e hábitos dos animais que interagem no processo de caça. Cunha et al. (2002) apontam que o caçador, por estabelecer uma relação próxima com os animais, desenvolve conhecimento sobre ecologia, distribuição, alimentação e comportamento da fauna cinegética, sendo capaz de reconhecer os rastros de diferentes animais.

De acordo com Campos (2008), a percepção dos caçadores sobre os hábitos diurnos e noturnos dos animais determina a escolha do horário para prática de caça e a melhor estratégia a ser utilizada, o que pode ser evidenciado nos depoimentos acima quando os caçadores relacionam o horário de caçar o teiú a seu hábito diurno. Observa-se ainda em alguns depoimentos a existência de restrição temporal para a caça de animais em período reprodutivo. Essa restrição foi documentada também em outros estudos (MENDONÇA, 2000; SANCHES, 2004; SCHIAVETTI, 2010; SANTOS et al., 2016). Essa prática é positiva para a conservação das espécies, uma vez que, se a caça ocorre em menor proporção, as populações de animais conseguirão recuperar-se da exploração (BODMER et al., 1997; PEREIRA; SCHIAVETTI, 2010). Segundo Alvard (1995), em um comportamento conservacionista, espera-se haver preferência por machos em relação às fêmeas, contribuindo para o recrutamento populacional da espécie. 
Relatos referentes a restrição de caça na sexta-feira podem estar relacionados à influência da tradição cristã, pois esse dia está relacionado à Paixão de Cristo. No provérbio é considerado como dia de luto, tristeza, dor, e um 'dia santo', sendo, portanto, de forte simbolismo e conotação religiosa (SVOBODOVÁ, 2011).

A respeito do conhecimento e percepção das comunidades sobre a natureza, chama a atenção para a existência de padrões que influenciam a forma como as populações interpretam a natureza ao redor. Entre esses fatores estão os sistemas culturais, os meios de produção, meios de comunicação e a linguagem, que, se não levados em consideração, poderão produzir interpretações equivocadas da realidade observada, uma vez que, mesmo sendo expressos em vocábulos similares, podem ter os significados alterados de acordo com as circunstâncias históricas e culturais das diferentes sociedades. Assim, questões como símbolo, mitos, produção e expressões culturais das populações são formas valiosas no estudo de percepção e consequentemente da interação do homem com o ecossistema.

Em relação às restrições de caça, os entrevistados citaram o cangambá, em função do cheiro forte; canção, por trazer má sorte ao caçador; tatupeba, considerado 'carregado', uma carne 'reimosa'. A expressão, reimosa é empregada para caracterizar alimentos cuja ingestão pode vir a causar problemas de saúde a pessoas enfermas ou a mulheres no período menstrual, de gravidez e de pós-parto (PEZZUTI, 2004; GALVAGNE-LOSS et al., 2014).

As carnes dos animais consideradas 'reimosas' têm o consumo evitado em diferentes regiões do Brasil (VOS, 1978; HANAZAKI, 2002; PEZZUTI, 2004; GALVAGNE-LOSS et al., 2014). Esse padrão de escolha dos alvos envolvidos na atividade cinegética não é moldado somente por uma questão energética entre custo e benefício (forrageador ótimo), mas também por mecanismos culturais (cultural simbólica e/ou cultural adaptativo), constituindo os tabus e preferências alimentares (SHEPARD, 2002). Regras como tabus e restrições de caça socialmente construídos pelas comunidades são importantes estratégias para uso sustentável dos recursos faunísticos, por disciplinarem a prática de caça, construindo assim um controle simbólico de acesso aos animais que vivem na mata (DIAS et al., 2004).

A existência desses tabus contribui não somente para a manutenção dos recursos faunísticos, mas também das comunidades que deles dependem para a sobrevivência (MORAN, 1974; BEGOSSI et al., 1992; COLDING et al., 1997; VIERA et al., 2015; GALVAGNE-LOSS et al., 2014). Os caçadores do povoado Cruz fizeram referência a lendas e entidades da floresta, mencionando a caipora como protetora dos animais, a quem devem "agradar" se assim desejarem ter sucesso na caçada.

Existe ainda uma simbologia associada ao couro do veado, do qual é feito uma correia que deve ser benzida por um rezador da comunidade e utilizado para proteção contra picadas de cobras. "Leva fumo e alho para colocar dentro do toco, aí diz que é para o pai do mato" (M-7). "Levar fumo pra caipora e uma correa curada. É uma correa de coro de veado, benze e leva pra proteger das cobra" (M-4). "Leva fumo para dá aos caboclos, se ouvir um assubi pode voltar que a caça não vai ser boa" (M-9). "A caipora esconde a caça, mata os cachorro, os cachorro fica assustado, latindo e acuando o toco, como se fosse alguma coisa, aí a 
gente vai lá e não tem nada" (M-2). "Reza de caipora e leva fumo pra ela" (M-6). "Todos que caçam tem que ter uma correa benzida para proteger de cobras" (M-1).

A caipora está representada no folclore brasileiro como um mito desde a época colonial, também conhecida como caiçara, curupira, pai ou mãe do mato, seu significado está relacionado à proteteção da caça e das matas (ALVES et al., 2007). Para Almeida (2013), a caipora é um ente das florestas que funciona como presuposto para a continuidade dos animais das matas, para regeneração e cura quando são feridos. Além de intermediar o acesso às caças, que ocorre pelo oferecimento de tabaco (LIMA, 1996; ALMEIDA, 2013).

Dessa forma, a caipora representa um elo entre os caçadores e a quantidade dos animais das matas, atuando como uma espécie de controle na extração sustentável dessa fauna, em virtude de regras e negociações para o acesso aos animais: a "(...) caipora cura a caça da bala dos caçadores, cuida e garante a reprodução dos animais, a quantidade e a diversidade da fauna" (DIAS, 2004). As regras para o acesso aos animais das florestas envolvem não caçar em dias considerados santos, evitar caçar determinadas espécies e não abusar da quantidade de animais caçados (ALMEIDA, 2013). Caso essas regras não sejam respeitadas, surgem punições aos agressores da natureza e aos caçadores que matam por prazer.

Os usos e os meios pelos quais os animais silvestres são explorados pelos seres humanos, bem como as tradições culturais que determinam as interações entre pessoas e animais, geram uma pressão maior ou menor nas populações exploradas (ALVES et al., 2008; ALVES et al., 2010). Portanto, os mitos presentes na cultura de determinada comunidade tradicional definem a forma como os recursos naturais são utilizados, o que torna o entendimento desses elementos importante no manejo dos recursos naturais (MAGALHÃES et al., 2014).

\section{CONCLUSÕES}

As representações da fauna cinegética na comunidade Cruz são caracterizadas por mitos, crenças, saberes e tabus alimentares, que constituem práticas culturais e ecológicas relevantes, uma vez que as crenças e o misticismo associados aos animais disciplinam a prática de caça e são importantes estratégias para o uso sustentável dos recursos faunísticos.

Costa Neto (2000) aponta que, mesmo com a interação mágico-religiosa estando presente em diversas culturas, os estudos têm negligenciado essa atividade pelo fato de ser considerada por muitos pesquisadores como folclore de comunidades indígenas e tradicionais; entretanto, pode apresentar-se como importante estratégia de conservação da fauna quando as interações envolvem restrições de uso devido à associação de divindades aos animais. Assim, a viabilização do uso sustentável dos recursos faunísticos requer um conhecimento por parte de ecólogos e conservacionistas das relações que as populações humanas mantêm com o meio ambiente, incluindo o sistema de mitos e crenças presentes nas diferentes sociedades.

\section{REFERÊNCIAS}

ALBUQUERQUE, U. P.; LUCENA, R. P.; ALENCAR, N. L.. Métodos e técnicas para a pesquisa etnobotânica. 2 ed. Recife: NUPEEA, 2008.
ALMEIDA, M. W. B.. Caipora e outros conflitos ontológicos. Revista de Antropologia da UFSCar, v.5, n.1, p.7-28, 2013. 
ALVARD, M. S.. Shotguns and sustainable hunting in the neotropics. Oryx, v.29. n.1, p.58-66, 1995.

ALVES, M. J. C.; PEREIRA, M. A.. Lendas e mitos do Brasil. Belo Horizonte: Tela e Texto, 2007.

ALVES, R. R. N.; SILVA, C. C.; ALVES, H. N.. Aspectos socioeconômicos do comércio de plantas e animais medicinais em área metropolitanas do Norte e Nordeste do Brasil. Revista de Biologia e Ciências da Terra, Campina Grande, v.8, n.1, p.181-189, 2008.

ALVES, R. R. N.; MENDONÇA, L. E. T.; CONFESSOR, M. V. A.; VIEIRA, W. L. S.; VIEIRA, K. S.; ALVES, F. N.. Caça no semiárido paraibano: uma abordagem etnozoológica. In: ALVES, R. R. N.; SOUTO, W. M. S; MOURÃO, J. S.. A etnozoologia no Brasil: importância, status atual e perspectivas. Recife: NUPPEA, 2010. p.347-378.

ALVES, R. R. N.; MENDONÇA, L. E. T.; CONFESSOR, M. V. A.; VIEIRA, W. L. S.; LOPEZ, L. C. S.. Hunting strategies used in the semi-arid region of northeastern Brazil. Journal of Ethnobiology and Ethnomedicine, London, v.5, n.12, p.1-50, 2009.

ANDRIGUETO-FILHO, J. M.; KRÜGER, A. C.; LANGE, M. B. R.. Caça, biodiversidade e gestão ambiental na área de proteção ambiental de Guaraqueçaba, Paraná, Brasil. Biotema, v.11, n.2, p.133-156, 1998.

BAILEY, K.. Methods of social research. New York: Free Press, 1994.

BAPTISTA, G. C. S.. Contribuições da etnobiologia para o ensino e a aprendizagem de ciências. Curitiba: Appris, 2015.

BEGOSSI, A.; RICHERSON, P. J.. The animal diet of families from Búzios Island (Brazil): an optimal foraging approach. Journal of Human Ecology, v.3, n.2, p.433-458, 1992.

BODMER, R. E.; EISENBERG, J. F.; REDFORD, K. H.. Hunting and the likelihood of extinction of Amazonian mammals. Conservation Biological, v.11, p.460-466, 1997.

CAMPOS, M. A. A.. Cruzando ecologias com os caçadores do Rio Negro, Amazonas. Dissertação (Mestrado em Biologia Tropical e Recursos Naturais) - Universidade Federal do Amazonas, Manaus, 2008.

CUNHA, M. C.; ALMEIDA, M. B.. Enciclopédia da Floresta: o Alto Juruá: práticas e conhecimentos das populações. São Paulo: Cia das Letras, 2002.

COLDING, J.; FOLKE, C.. The relations among threatened species, their protection, and taboos. Conservation Ecology, v.1, n.1, 1997.

COSTA NETO, E. M.. Conhecimento e usos tradicionais de recursos faunísticos por uma comunidade afro-brasileira. Resultados preliminares. Interciencia, Caracas, v.25, n.9, p.423-431, 2000.

DIAS, C. J.. Na floresta onde vivem brabos e mansos: economia simbólica de acesso à natureza praticada na Reserva Extrativista do Alto Juruá - Acre. Dissertação (Mestrado em Antropologia Social) - Universidade Estadual de Campinas, Campinas, 2004.
DIAS, C. J.; ALMEIDA, M. W. B.. A floresta como mercado: caça e conflitos na Reserva Extrativista do Alto Juruá Acre. Boletim Rede Amazônica, Rio de Janeiro, v.3, n.1, p.927, 2004

DIEGUES, A. C.; ARRUDA, R. S. V.. Saberes tradicionais e biodiversidade no Brasil. Brasília: Ministério do Meio Ambiente, 2007.

DREWS, C.. Simpatía y empatía hacia la fauna silvestre: las raices de la tenência de mascotas silvestres. In: DREWS, C.. Rescate de fauna silvestre em el Neotrópicos. Heredia: Universidad Nacional, 1991. p.31-51.

GALVAGNE-LOSS, A. T.; COSTA NETO, E. M.; FLORES, F. M. Aves silvestres utilizadas como recurso trófico pelos moradores do povoado de Pedra Branca, Santa Teresinha, Bahia, Brasil. Gaia Scientia, v.1, n.14, 2014.

HANAZAKI, N.. Preferências e tabus alimentares entre pescadores do litoral paulista: particularidades do conhecimento local. In: SIMPÓSIO BRASILEIRO DE ETNOBIOLOGIA E ETNOECOLOGIA, 4. Anais. Recife: Sociedade Brasileira de Etnobiologia e Etnoecologia, 2002.

LEFF, E.. Ecologia, capital e cultura: a territorialização da racionalidade ambiental. Petrópolis: 2009.

LIMA, T. S.. Os dois e seu múltiplo: reflexões sobre o perspectivismo em uma cosmologia Tupi. Mana, v.2, n.21, p.21-47, 1996.

LIMA, J. R. B.; SANTOS, C. A. B.. Recursos animais utilizados na medicina tradicional dos índios Pankararu no nordeste do Estado de Pernambuco, Brasil. Etnobiología, Cidade do México, v.8, p.39-50, 2010.

MAGALHÃES, H. F.; COSTA-NETO, E. M.; SCHIAVETTI, A. Cosmovisão e etnoconservação nos manguezais do município de conde, litoral norte do estado da Bahia, Brasil. Etnobiología, Cidade do México, v.12, n.1, 2014.

MARQUES, J. G. W.. Pescando pescadores: etnoecologia abrangente no baixo São Francisco alagoano. São Paulo: USP, 1995.

MARQUES, J. G. W.. Aspectos ecológicos na etnoictiologia dos pescadores do Complexo Estuarino-lagunar MundaúManguaba. Tese (Doutorado em Ecologia) - Universidade Estadual de Campinas, Campinas, 1991.

MENDONÇA, L. E. T.; SOUTO, C. M.; ANDRELINO, L. L.; SOUTO, W. M. S.; VIEIRA, W. L. S.; ALVES, R. R. N.. Conflitos entre pessoas e animais silvestres no semiárido paraibano e suas implicações para conservação. Sitientibus Série Ciências Biológicas, v.11, n.2, p.185-199, 2011.

MORAN, E.. The adaptive system of the Amazonian caboclo. In: WAGLEY, C.. Man in the Amazon. Gainesville: University of Florida Press, 1974.

MOSCOVICl, S.. Representações sociais: investigações em psicologia social. Rio de Janeiro: Vozes, 2005.

PEREIRA, J. P. R.; SCHIAVETTI, A.. Conhecimentos e usos da fauna cinegética pelos caçadores indígenas 'Tupinambá de Olivença' (Bahia). Biota Neotrópica, v.10, n.1, 2010. 
PEZZUTI, J. C. B.; LIMA, J. P.; SILVA, D. F.; REBELO, G. H.. A caça e a pesca no Parque Nacional do Jaú. In: BORGES, S. H.. Janelas para a biodiversidade no Parque Nacional do Jaú: uma estratégia para o estudo da biodiversidade na Amazônia. Manaus: Fundação Vitória Amazônica, p.213-230, 2004.

PEZZUTI, J. C. B.. Manejo de caça e a conservação da fauna silvestre com participação comunitária. Belém: UFPA, 2009.

POSEY, D. A.. Hierarchy and utility in a folk biological taxonomic system: patterns in classification of arthropods by the Kayapo Indians of Brazil. Journal of Ethobiology, v.4, n.2, p.123-139, 1984.

REIGOTA, M.. Meio ambiente e representação social. São Paulo: Cortez, 2010.

SANCHES, R. A.. Caiçara e a Estação Ecológica Juréia-Itatins: histórico de ocupação no contexto político, econômico, social e ambiental no Vale da Ribeira. In: MARQUES, O.A.V.; DULEBA, W.. Estação Ecológica Juréia-Itatins: ambiente físico, flora e fauna. Ribeirão Preto: Holos, 2004. p.349-357.

SANTOS-FITA, D.; COSTA NETO, E. M.. As interações entre os seres humanos e os animais: a contribuição da etnozoologia. Biotemas, Florianópolis, v.20, p.99-110, 2007.

SANTOS, C. A. B; ALBUQUERQUE, U. P.; SOUTO, W. M. S.; ALVES, R. R. N.. Assessing the effects of indigenous migration on zootherapeutic practices in the semiarid region of Brazil. PLOS ONE, v.11, n.1, 2016. DOI:

http://10.1371/journal.pone.0146657

SANTOS, C. A. B.. Padrões de caça, pesca e uso de animais silvestres pela etnia Truká, no semiárido brasileiro. Tese (Doutorado em Etnobiologia e Conservação da Natureza) Universidade Federal Rural de Pernambuco, Recife, 2016.

SHEPARD, G. H.. Primates in Matsigenka subsistence and world view. Cambridge Studies in Biological and Evolutionary Anthropology, Cambridge, p.101-136, 2002.

SVOBODOVÁ, I.. Abordagem histórica dos nomes dos dias da semana: análise sintático-semântica. CONGRESSO ALEMÃO DE LUSITANISTAS, 9. Anais. Wien: Universidade de Viena, 2011.

VERDADE, L. M.. A exploração da fauna silvestre no Brasil: jacarés, sistemas e recursos humanos. Biota Neotropica, v.4, n.2, 2004.

VIEIRA, M. A.; MUHLEN, E. M.; SHEPARD, G. H.. Participatory monitoring and management of subsistence hunting in the Piagaçu - Purus Reserve, Brazil. Conservation and Society, v.13, p.254, 2015.

VOS, A.. La caza como fuente de alimento. Unasylia, v.29, n.116, 1978. 